\title{
Laboutarie
}

Tumulus T2 de Lacombe

\section{Christian Servelle}

\section{(2) OpenEdition}

12 Journals

Édition électronique

URL : http://journals.openedition.org/adlfi/10286

ISSN : 2114-0502

Éditeur

Ministère de la culture

Référence électronique

Christian Servelle, «Laboutarie », ADLFI. Archéologie de la France - Informations [En ligne], MidiPyrénées, mis en ligne le 01 mars 1997, consulté le 19 avril 2019. URL : http:// journals.openedition.org/adlfi/10286

Ce document a été généré automatiquement le 19 avril 2019.

(c) Ministère de la Culture et de la Communication, CNRS 


\title{
Laboutarie
}

\author{
Tumulus T2 de Lacombe
}

\section{Christian Servelle}

Date de l'opération : 1990 (SU)

Inventeur(s) : Servelle Christian

1 L'existence d'une sépulture tumulaire à l'emplacement d'un relief à peine marqué émergeant de la surface du plateau calcaire de Sieurac fut maintes fois évoquée lors de la fouille du dolmen T1 de Lacombe, monument situé à moins de $200 \mathrm{~m}$ de là. Une aire grossièrement ovoïde d'une douzaine de mètres de long sur près de $7 \mathrm{~m}$ de large était caractérisée par une anormale densité de pierres à la surface du sol de la lande.

Le monument fut fouillé dans son intégralité ainsi que ses abords immédiats, sur une largeur de $1 \mathrm{~m}$ environ, soit une superficie totale de $102 \mathrm{~m}^{2}$ environ (Fig. $\mathrm{n}^{\circ} 1$ : Plan d'ensemble du tumulus T1). Le tertre composé de pierrailles hétérométriques et de blocs affecte une forme ovolaire. Il est orienté nord-nord-ouest/sud-sud-est. Le secteur central, le plus épais, montre la superposition de trois niveaux de pierres. Les éléments de la base du monument reposaient directement sur le substratum rocheux lapiazé ou corrodé. Les matériaux employés pour la construction du tertre sont issus des formations calcaires et gréseuses qui affleurent dans les corniches limitant le plateau ou qui parsèment la surface du petit causse tertiaire. Ces dallettes destinées à des aménagements particuliers ont été soigneusement sélectionnées. Une structure naviforme de la taille d'un homme et orientée nord-ouest-sud-est fut construite à l'aide de dallettes disposées à plat dans la partie médiane et placées avec un net pendage du le centre à la périphérie. Les vestiges osseux et céramique qui y ont été recueillis sont rares et fragmentés. S'agit-il d'une tombe ayant subi une violation peu de temps après sa mise en place ? Est-ce un emplacement lié au dépôt provisoire des cadavres avant leur destination définitive?

3 Une tombe fut découverte dans l'angle sud-ouest du tumulus. Les labours anciens et modernes l'avaient fortement dégradé. Il ne subsistait que de rares éléments latéraux et verticaux du caisson. Sur le dallage de base reposaient sans continuité les restes osseux d'un individu. À ses pieds, un vase polypode écrasé sur place était encore décelable. Près 
du crâne, une meule en grés était disposée à plat. À l'extérieur du caisson un récipient en céramique avait dû être déposé. Il était réduit à l'état de tessons de petites dimensions. Les éléments les plus remarquables de cette sépulture étaient constitués par trois anneaux et quatre bracelets en bronze, deux bracelets ouverts à hauts effilés et deux tiges à rond enroulées en spirale.

4 Cette inhumation datée du Bronze moyen, est-elle contemporaine de la construction du tumulus? Elle a pu fort bien (sépulture adventice) se greffer à une structure funéraire déjà existante. Elle témoigne néanmoins de la persistance des activités sépulcrales sur cette portion du plateau calcaire depuis le Chalcolithique avec le dolmen voisin jusqu'au milieu de l'Âge du bronze. Le tumulus T2 de Lacombe est lié, incontestablement, à des pratiques funéraires. On peut cependant s'interroger sur l'époque de l'édification du tertre. La structure naviforme vidée de son contenu à une période indéterminée, peutêtre peu de temps après son utilisation, étant donné le nettoyage dont elle a été l'objet, a une destination énigmatique.

\section{ANNEXES}

Fig. $n^{\circ} 1$ : Plan d'ensemble du tumulus $\mathrm{T} 1$

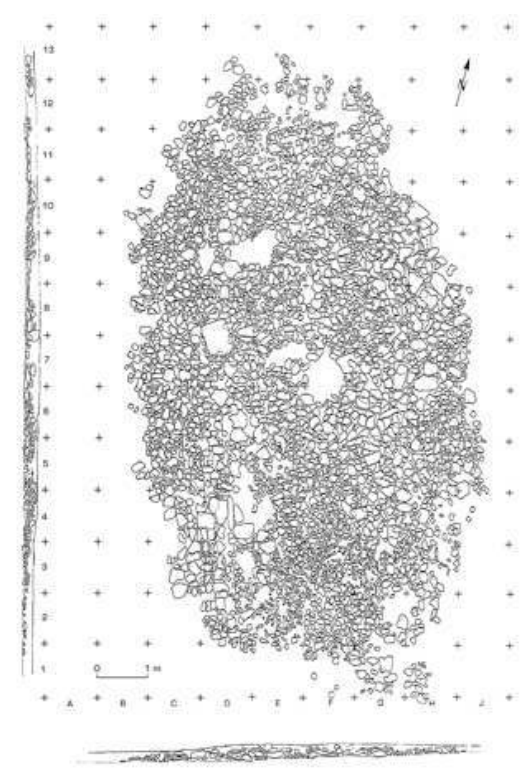


INDEX

Index chronologique : Bronze moyen

Index géographique : Midi-Pyrénées, Tarn (81), Laboutarie

operation Sauvetage urgent (SU) 